\title{
Oppression or Protection: Reflecting on Medicine and Justice Through Narrative Medicine
}

\author{
Haley Newman ${ }^{1}$, Caroline Diorio ${ }^{1}$, Daniel Eison ${ }^{1}$, Haley Faust ${ }^{1}$, Suzanne MacFarland ${ }^{2}$, \\ Laura Palmer ${ }^{2}$, Madhura Pradhan ${ }^{1}$, and Leslie Kersun ${ }^{2}$ \\ ${ }^{1}$ Children's Hospital of Philadelphia \\ ${ }^{2}$ The Children's Hospital of Philadelphia
}

October 24, 2021

\begin{abstract}
Early in the Coronavirus Disease 2019 pandemic, our medical center, like many, halted in-person learning activities. The narrative medicine sessions we planned for the pediatric hematology/oncology fellows were no exception. At this time we also witnessed waves of civil unrest fueled by systemic racism toward Americans of color. Amidst the isolation, apprehension, and turmoil, we turned to narrative medicine. To keep our participants safe and work around novel constraints, we adapted the narrative medicine curriculum for virtual delivery.
\end{abstract}

\section{Hosted file}

PBC SUBMISSION_HN.docx available at https://authorea.com/users/442582/articles/542821oppression-or-protection-reflecting-on-medicine-and-justice-through-narrative-medicine 